Portland State University

PDXScholar

\title{
Approaching the Transition to Adulthood: Distinctive Profiles of Adolescents Aging out of the Child Welfare System
}

\author{
Thomas E. Keller \\ Portland State University, kellert@pdx.edu \\ Gretchen Ruth Cusick \\ University of Chicago \\ Mark E. Courtney \\ University of Chicago
}

Follow this and additional works at: https://pdxscholar.library.pdx.edu/socwork_fac

Part of the Social Work Commons

Let us know how access to this document benefits you.

Citation Details

Keller, T.E., Cusick, G.R., Courtney, M.E. (2007). Approaching the transition to adulthood: Distinctive profiles of adolescents aging out of the child welfare system. Social Service Review, 81 (3), 453-484.

This Article is brought to you for free and open access. It has been accepted for inclusion in Social Work Faculty Publications and Presentations by an authorized administrator of PDXScholar. Please contact us if we can make this document more accessible: pdxscholar@pdx.edu. 


\section{CHICAGO JOURNALS}

Approaching the Transition to Adulthood: Distinctive Profiles of Adolescents Aging out of the Child Welfare System

Author(s): Thomas E. Keller, Gretchen Ruth Cusick, and Mark E. Courtney

Reviewed work(s):

Source: Social Service Review, Vol. 81, No. 3 (September 2007), pp. 453-484

Published by: The University of Chicago Press

Stable URL: http://www.jstor.org/stable/10.1086/519536

Accessed: 15/02/2013 19:18

Your use of the JSTOR archive indicates your acceptance of the Terms \& Conditions of Use, available at http://www.jstor.org/page/info/about/policies/terms.jsp

JSTOR is a not-for-profit service that helps scholars, researchers, and students discover, use, and build upon a wide range of content in a trusted digital archive. We use information technology and tools to increase productivity and facilitate new forms of scholarship. For more information about JSTOR, please contact support@jstor.org. 


\title{
Approaching the Transition to Adulthood: Distinctive Profiles of Adolescents Aging out of the Child Welfare System
}

\author{
Thomas E. Keller \\ Portland State University \\ Gretchen Ruth Cusick \\ Chapin Hall Center for Children at the University of Chicago \\ Mark E. Courtney \\ University of Chicago
}

\begin{abstract}
The transition to adulthood is marked by new roles and responsibilities in such interrelated domains as education, employment, and family formation. This study investigates the capacity of adolescents on the verge of emancipation from the child welfare system to navigate this transition. To explore heterogeneity in adolescents' preparation for independent living, person-oriented methods are applied to a large, representative sample of youth about to exit foster care. The analysis suggests four subpopulations defined by distinctive profiles on indicators reflecting multiple domains of life experience. Identifying the particular needs and challenges of subpopulations has implications for efforts to match adolescents aging out of the child welfare system with appropriate services.
\end{abstract}

During the transition from adolescence to adulthood, increasing maturity comes with expectations that one will take responsibility for oneself, make independent decisions, and become self-sufficient (Arnett 2000). In this period, young people contend with multiple opportunities and challenges that can have important implications over the life course. Individual developmental pathways are determined by decisions regarding education, employment, residential arrangements, marriage, and parenthood (Shanahan 2000; Cohen et al. 2003). Important

Social Service Review (September 2007).

(C) 2007 by The University of Chicago. All rights reserved.

0037-7961/2007/8103-0004\$10.00 
changes in social roles and responsibilities can generate stress and test an individual's capacity for adaptation, but these changes also present opportunities to overcome earlier difficulties and to begin on a new developmental trajectory (Maughan and Champion 1990; Masten et al. 2004).

For each generation, cultural expectations and social opportunity structures influence the timing and patterning of role entries and exits during the transition to adulthood (George 1993; Elder 1998). In recent years, early adulthood has been characterized as a period of volitional identity exploration that involves "trying out various life possibilities and gradually moving toward making enduring decisions" (Arnett 2000, 473). However, the life circumstances of many young people may severely limit their range of options or compel them, out of necessity, to adopt adult roles at an early age. Pathways to adulthood are strongly linked with social class, as well as with the resources and support of one's family of origin (Cohen et al. 2003; Osgood et al. 2005). For example, poverty and family disruption may cause young people to move away from home and support themselves at an early age, perhaps interrupting their education and restricting their future options with respect to career and family formation (Goldscheider and Goldscheider 1998). From a developmental perspective, these early, off-time transitions, for which youth are not well prepared, have the potential to compound environmental adversity, threaten coping capacity, tax social supports, and compel individuals to enter into situations that may constrain their long-term prospects (Maughan and Champion 1990).

Young people forced from the child welfare system at age 18 are a population of special interest from a developmental perspective because they must negotiate the transition to adulthood suddenly and without guarantees of continuing support. Emancipation represents an abrupt discontinuity in caregiving. For most youth, maintaining connections to parent figures and being able to rely upon them in times of adversity contribute to positive adjustment throughout adolescence and the transition to adulthood (Steinberg 1990; Allen and Land 1999). Adolescent independence and self-reliance, as well as educational and occupational achievement, are associated with strong relationships with parents that feature both close emotional connection and support for autonomy (Bell et al. 1996; O'Connor et al. 1996). Furthermore, many young people who leave their parents during the transition to adulthood, particularly those who move out at an early age, may return at various times to live in the family home, using it as a safety net or a base for launching into new roles (White 1994). Likewise, caregiving adults can provide valuable guidance in navigating important decisions during the transition to adulthood (Csikszentmihalyi and Schneider 2000), and many individuals rely heavily on their families for material assistance in early adulthood (Schoeni and Ross 2005). In contrast to young people who 
can count on consistent family support, those who experience family instability in the form of separations from parents, residential moves, and family conflict are more likely to demonstrate difficulties in numerous developmental domains (Musick and Bumpass 1999; Keller et al. 2002; Adam 2004).

Young people exiting foster care are likely to have life histories that reflect family instability in combination with multiple other factors (e.g., poverty, poor parenting, and poor bonding to parents, schools, and communities) that are associated with problematic developmental outcomes (Buehler et al. 2000; Harden 2004). Many adolescents in state care have suffered abuse, neglect, abandonment, or loss of a parent (Pecora, Whittaker, and Maluccio 1992). In addition, initial placement in a foster home or residential facility involves separation from family and familiar settings. Many foster youth experience inconsistent parenting, school transitions, and other difficulties associated with placement, particularly when foster placement disruptions cause subsequent moves (Fein, Maluccio, and Kluger 1990). Such histories suggest that youth aging out of the child welfare system may face considerable challenges during the transition to adulthood (Collins 2001; Mech 2003). Nevertheless, when youth reach the age of majority and are emancipated from state care, their access to basic resources (e.g., housing), to opportunities (e.g., education), and to treatment and support services (e.g., mental health counseling) declines substantially (Courtney et al. 2001).

Adolescents in their final years of state custody and adults formerly in foster care have generally low levels of educational and occupational attainment, as well as relatively high rates of negative outcomes. Such findings correspond to the many challenges that these individuals face. Studies suggest that many youth who age out of the foster care system are ill prepared for adult roles in terms of educational completion, independent living skills, and job preparedness; substantial percentages experience homelessness, victimization, incarceration, and nonmarital parenthood (Barth 1990; Cook, Fleishman, and Grimes 1991; McMillen and Tucker 1999; Buehler et al. 2000; Courtney et al. 2001). For the most part, evidence suggesting high rates of problematic outcomes in the transition to adulthood comes from studies that report statistics in the aggregate. However, even if involvement in the child welfare system confers or signifies a high probability of future problems, youth in foster care are likely to follow divergent pathways. A probabilistic rather than deterministic perspective on development implies that a single factor is rarely a necessary or sufficient cause of difficulties and that a single factor can contribute to different outcomes among different individuals (Cicchetti and Cohen 1995; Sroufe 1997). Thus, common experiences in foster care may interact with individual dispositions and circumstances, resulting in very different consequences. Furthermore, individ- 
uals' experiences of foster care may vary substantially according to the number, type, and duration of their placements (Wulczyn, Kogan, and Harden 2003). However, few studies investigate the heterogeneity that is bound to exist in the child welfare population.

Another feature of previous studies of late-adolescent and former foster youth is that variables such as education, employment, parenthood, and incarceration have been reported as isolated indicators of functioning and development. However, a probabilistic perspective on development implies that individual adaptation is a function of the combination and interaction of multiple contributing factors (Cicchetti and Cohen 1995; Sroufe 1997). The capacity of individuals to navigate the transition from adolescence to adulthood is likely to depend on their distinctive patterns of past experiences and current circumstances (Cicchetti and Rogosch 2002). In other words, the transition to adulthood involves interactions, interconnections, and mutual influences among such life domains as education, employment, and parenting (Maughan and Champion 1990; Gore et al. 1997). For example, grade repetition and problem behaviors may reduce the likelihood of adolescent employment (Leventhal, Graber, and Brooks-Gunn 2001). Gaining work experience during adolescence may provide valuable preparation for future employment if such experience complements rather than detracts from educational progress. Work experience also may be valuable if it promotes the development of values and skills instead of introducing precocious behaviors, such as dating, drinking, or delinquency, through association with adults (Mortimer, Harley, and Aronson 1999). Likewise, difficulties with family, negative experiences in school, and problem behaviors are associated with early pregnancy. In turn, early parenthood can have implications for subsequent educational attainment and employment options; it also can increase the need for family support and resources (Brooks-Gunn and Chase-Lansdale 1995; Coley and Chase-Lansdale 1998). Thus, prospects for the transition to adulthood are best reflected in analyses that simultaneously incorporate multiple domains of life experience.

A person-oriented approach to analysis is consistent with this type of holistic perspective on individual functioning (Magnusson 1995). A basic premise of the person-oriented approach is that developmental processes must be understood by examining a system of mutually interacting factors because each factor derives its meaning and significance from its relations to the others (Magnusson 1998). Development is a process characterized by states that change over time, and a state is the specific configuration of the system at a specific time (Bergman and Magnusson 1997). Despite infinite possibilities, history and circumstance constrain systems to self-organize into a relatively small number of coherent patterns. Thus, emphasis is placed on identifying and examining lawful 
regularities and organized configurations of interactive factors that distinguish qualitatively different groups of individuals (Bergman, Magnusson, and El-Khouri 2003). For example, latent class analysis (LCA) models heterogeneity by using a latent categorical variable to represent a mixture of subpopulations differentiated by their particular patterns on multiple indicators (Gibson 1959; McCutcheon 1987). The result is an empirical classification of individuals who share a common profile.

Identifying specific subpopulations of youth based on their prospects for the transition to adulthood has great relevance for child welfare policy and practice relating to wards aging out of care. On the level of theory, specific multidimensional profiles indicate which factors are likely to co-occur in certain combinations at the individual level. As with a qualitative study that allows a comprehensive picture to emerge from the data, the systematic observation, identification, and description of regularities and patterns are valuable for generating hypotheses regarding processes that lead to or follow from an individual's current status (Bronfenbrenner and Morris 1998). On a practical level, it is not realistic to implement a one-size-fits-all approach to child welfare policy and practice. Identifying distinctive subpopulations characterized by particular combinations of strengths and challenges provides a basis for tailoring programs and services to the needs of different types of youth in the system (Foster and Gifford 2005; Settersten 2005). In addition, knowledge of the relative size of each subpopulation facilitates a strategic allocation of resources.

The present study adopts a person-oriented approach to investigate heterogeneity in a large, representative sample of youth who are aging out of the child welfare systems of three midwestern states. The aim is to distinguish meaningful subpopulations by examining their capacities for making the transition to adulthood. In assessing capacities, this research uses domains commonly viewed as markers of normative functioning in contemporary U.S. society. Such domains include school, work, and family. Latent class analysis is employed to generate distinctive multidimensional profiles on several factors that reflect adaptation in systemic interactions with relevant social institutions. For example, indicators include educational progress, employment experience, and parenthood. Likewise, indicators reflect experience in the child welfare system because a young person's connection to caregivers is likely to influence and reflect the internal capacities and external supports that he or she brings to the transition to adulthood. Finally, the analysis includes an indicator of serious problem behavior because such behavior signifies a clash with social norms and can complicate the transition to adulthood. The result is an empirical classification of adolescents in outof-home care that reflects a more holistic assessment of their status prior to leaving out-of-home care than is provided by previous research. 


\section{Method}

\section{Sample and Procedures}

The data are from the baseline interview of a longitudinal panel study that tracks a cohort of youth exiting the public child welfare systems of three midwestern states: Illinois, Iowa, and Wisconsin (Courtney, Terao, and Bost 2004; Courtney et al. 2005). The purpose of the study is to determine how well these adolescents are prepared for the transition to independent living. To date, this is the largest known prospective study of youth leaving care. The population of interest consists of adolescents who (1) are in out-of-home care supervised by the public child welfare agencies of the three states, (2) are 17 years or older at time of recruitment, and (3) were in out-of-home care for at least 1 year prior to recruitment. These conditions make it likely that the youth will be emancipated from the child welfare system to independence on or after their eighteenth birthdays. Youth are excluded if they are incarcerated, in an inpatient psychiatric institution, or have a developmental disability. Incarcerated individuals are not included because their involvement with the criminal justice system suggests that they are not necessarily on their way to independence in the community. Similarly, youth who are institutionalized or in special programs due to developmental disability are considered likely to have very different experiences from other youth. Specifically, these youth are likely to have different experiences of emancipation, to have different needs for continuing social services, and to have different expectations for independent living. Thus, the findings reported in this article reflect a specific population: youth who are aging out of the child welfare system and bound for independent living.

A representative sample was obtained using a systematic sampling procedure (Henry 1990). During the period from April 2002 to June 2002, the public child welfare agencies in the three states identified all active cases that met the inclusion criteria. The sampling frame included all eligible youth in two of the states (Iowa, Wisconsin), as well as a random selection of 67 percent of eligible youth in the third state (Illinois), which is the most populous of the three states. The foster care providers of the identified youth were informed of the study through a letter and through verbal communication from the youth's caseworker. Youth participants were sent letters informing them of the study and then were contacted for in-person interviews. Prior to each interview, written informed consent was obtained. All recruitment and data collection activities followed protocols approved by the relevant institutional review board of the University of Chicago.

By study design, state child welfare agency referrals of potential participants were not intended to include adjudicated delinquents, but 
agency records were sometimes out of date. In some cases, the initial contact with potential participants revealed that they were ineligible. Of the 880 adolescents identified for recruitment into the study, 110 of those contacted were discovered to be ineligible and were excluded for the following reasons: 40 were incarcerated or in a lockdown facility (e.g., psychiatric hospital), 33 were excluded due to physical or mental disability, 16 had run away or were missing from their assigned home prior to start of field period, 13 were out of state prior to start of field period, and 8 were ineligible for other reasons (e.g., adopted). Of the remaining 770 cases, 732 consented to participate and completed an in-person baseline interview. The result is a response rate of 95 percent.

The sample is evenly divided among males ( 48.5 percent) and females (51.5 percent). The mean age at the baseline interview was 17.4 years $(\mathrm{SD}=.50)$. Most respondents were 17 years of age (59.0 percent), and the rest were 18 years old ( 41.0 percent). The mean age at which respondents entered the child welfare system was 10.8 years $(\mathrm{SD}=4.0)$. A majority of the sample is African American (57.3 percent), followed by Caucasian (31.0 percent), mixed race (9.8 percent), American Indian or Native Alaskan (1.4 percent), and Asian or Pacific Islander (0.5 percent). Of those identifying Hispanic ethnicity (8.6 percent), most were of mixed race (50.8 percent); 23.8 percent were Caucasian, and 19 percent were African American. At the time of the baseline interview, 30.5 percent were in kinship foster homes (i.e., with relatives), 35.8 percent were in foster homes with nonrelatives, 18.1 percent were in group care or residential treatment facilities, 8.6 percent were in an independent living arrangement, 0.7 percent were in an adoptive home (prefinalization), and 6.3 percent were in some other setting.

\section{Measures}

Because different pathways to adulthood are the product of the past experiences and current circumstances of youth aging out of the child welfare system, the analysis examines seven indicators of individual status just prior to the transition to independent living. The authors intentionally selected straightforward indicators that draw on information readily available in the case records of young people in out-of-home care.

Employment.-A dichotomous variable indicates whether the respondent reported that he or she ever was employed in a job for pay. Employment history is ascertained by two questions that ask whether the respondent was employed at the time of the interview or had previously held a job.

Grade retention.-A dichotomous variable indicates whether a respondent has a history of grade retention. The variable is based on responses 
to the question, "Have you ever repeated a grade or been held back a grade?"

Parenthood.-A dichotomous variable for parenthood designates whether a respondent reported that he or she was a parent at the time of the interview. This indicator reflects responses to a question asked of both male and female respondents: "Do you have any living children?"

Problem behavior.-A dichotomous variable represents a history of problem behavior as indicated by a respondent's experience of official sanctions. Respondents are asked whether they ever were expelled from school and whether they ever spent time in jail. An affirmative response to either question indicates problem behavior.

Placement type.-A categorical variable represents the respondent's type of placement at the time of the interview. Three categories were created to organize the types of placements indicated by respondents: (1) kinship foster care (i.e., with relatives); (2) foster care with nonrelatives; or (3) nonfamily and other types of placement, which can include group homes, residential treatment centers, and independent living arrangements. Although this last category is heterogeneous, the number of living arrangements with relatively small distributions is constrained for methodological and conceptual reasons. The majority of youth in this category require nontraditional, nonfamily placements. Compared with youth in the two other care categories, these youth have higher levels of contact with and supervision from professional staff. The parental role of the state is more apparent in these cases.

Placement stability.-Placement stability is measured by an ordinal variable with three levels (0-1 placement, 2-4 placements, or 5 or more placements). Classification is based on responses to the question, "How many different foster homes, group homes, or residential treatment centers have you been in since first entering the foster care system?"

Runaway history.-A dichotomous variable indicates whether respondents have a history of absconding from placements. This indicator reflects responses to the question, "Have you ever run away from a foster home or group home (by run away, we mean staying away for at least one night)?"

\section{Analytic Strategy}

Latent class analysis is a model-based method in which observed variables are presumed to be indicators of a latent categorical variable that represents a mixture of distinct subpopulations within the data (Gibson 1959; McCutcheon 1987). The LCA method accounts for associations among observed variables by dividing a sample into classes within which there is no association among the variables (i.e., local independence). Thus, members of a latent class are relatively homogeneous, and random variation occurs around the class center. Between-class differences are 
Table 1

Model-Fit Statistic Comparisons

\begin{tabular}{lccccc}
\hline & $\mathrm{L}^{2}$ & $\mathrm{df}$ & $p$-value & Bootstrap $p$-value & BIC \\
\hline 1 class & 526.50 & 278 & $<.001$ & $<.001$ & $7,352.61$ \\
2 classes & 325.32 & 269 & .01 & .001 & $7,210.65$ \\
3 classes & 292.96 & 260 & .08 & .036 & $7,237.51$ \\
4 classes & 270.18 & 251 & .19 & .116 & $7,273.94$ \\
5 classes & 256.04 & 242 & .26 & .226 & $7,319.01$ \\
\hline
\end{tabular}

Note. - BIC $=$ Bayesian Information Criterion; $\mathrm{L}^{2}=$ likelihood ratio chi-square statistic; df $=$ degrees of freedom.

signified by different profiles of probabilities on the indicators. For LCA, the specified model designates the number of classes and constrains associations among all variables within each class. Given the specified model and starting values, the program employs an iterative maximum likelihood procedure to optimize classification of individual cases to latent classes. The estimation technique allows calculation of a likelihood ratio chi-square statistic $\left(\mathrm{L}^{2}\right)$ that indicates how well the solution for a given model fits the data. The Bayesian Information Criterion (BIC), which imposes a penalty for the number of parameters estimated, also can be used to compare models that have differing numbers of classes (Raftery 1995). The BIC index emphasizes a parsimonious fit to the data. There are other considerations in selecting the preferred solution (Muthen and Muthen 2000). The final model should have high classification quality and practical utility. Utility is assessed in terms of adequate class sizes and theoretical interpretability. The analyses are conducted using Latent GOLD software (Vermunt and Magidson 2005).

\section{Results}

\section{Model Selection and Case Assignment}

The model-fit statistics for five different models are presented in table $1{ }^{1}$ The fit statistics suggest that at least three classes are necessary to provide a good fit to the data (alpha of $p<.05$ for one- and two-class models rejects the null hypothesis of model and data equivalence). The least discrepancy between model and data occurs in the five-class model, but the lower BIC values for three-class and four-class models indicate that they provide more parsimonious solutions. Although the three-class model is more parsimonious than the four-class model, the latter is selected because it ultimately has a better fit to the data. ${ }^{2}$ The quality of model fit is investigated in detail by deriving nonparametric bootstrap $p$-values, which offer improved precision by relaxing the assumption that $\mathrm{L}^{2}$ follows the chi-square distribution if the total number of cells is 
large relative to sample size (Magidson and Vermunt 2004). Bootstrap values for each model are based on the same five hundred replication samples. These values lead to the rejection of model fit for the threeclass model $(p<.05)$ but not for that of the four-class model $(p>.10)$. In addition, the Latent GOLD program permits calculation of a conditional bootstrap to assess whether a more restricted model provides a statistically significant improvement in model fit (Vermunt and Magidson 2005). Results (not shown) indicate that the four-class model demonstrates statistically significant improvement over the three-class model $(p<.05)$. Consequently, the four-class model is preferred because, as described below, it provides greater certainty in classification of cases. Finally, the four-class model yields classes that are substantively informative. The meaningful distinctions among classes that support this claim are presented below in the description of the class profiles and in the analyses that validate important differences among the groups.

For each individual case, LCA yields posterior probabilities that indicate the likelihood of membership in each of the classes. For example, the probabilities that a given individual belongs to class $1,2,3$, or 4 may be $0.85,0.02,0.10$, and 0.03 , respectively. For reporting the profiles of the classes on the indicators used in the analysis and for validating class distinctions on a separate set of variables, cases are assigned to membership in the single class for which they have the highest, or modal, probability. The need to assign individual cases to discrete classes is one reason for prioritizing model fit over parsimony. With good model fit, differences between weighted probability assignment and discrete, modal assignment are relatively minor. ${ }^{3}$

\section{Description of Classes and Profiles}

The profile of each latent class in the empirically derived four-class solution is presented in table 2. The first row shows the relative proportion of the sample in each class. The remaining rows present the probabilities on the variables used in the LCA.

Latent class 1 .-The largest class, representing approximately 43 percent of the sample, reports particularly notable experiences with the child welfare system. The adolescents in this group are much more likely than those in any other class to report that they live in nonfamily or other nontraditional care arrangements (e.g., group care, independent living), have had more than five placements, and have run away from a placement. In addition, respondents in this class report a high rate of problem behavior, as reflected in school expulsions and juvenile detention. Finally, employment and grade retention figures are slightly less favorable for class 1 respondents than they are for the full sample.

Latent class 2.-The second-largest class, with about 38 percent of the 
Table 2

Profiles of the Latent Classes on Classification Variables

\begin{tabular}{|c|c|c|c|c|c|}
\hline & Class 1 & Class 2 & Class 3 & Class 4 & Totals \\
\hline Proportion of sample & .433 & .378 & .142 & .046 & 1.0 \\
\hline \multicolumn{6}{|l|}{ Employment (ever): } \\
\hline Yes & .814 & .935 & .856 & .029 & .829 \\
\hline No & .186 & .065 & .144 & .971 & .171 \\
\hline \multicolumn{6}{|l|}{ Grade retention: } \\
\hline Yes & .405 & .199 & .663 & .618 & .374 \\
\hline No & .595 & .801 & .337 & .382 & .626 \\
\hline \multicolumn{6}{|l|}{ Parenthood: } \\
\hline Yes & .146 & .117 & .097 & .412 & .140 \\
\hline No & .854 & .883 & .903 & .588 & .860 \\
\hline \multicolumn{6}{|l|}{ Problem behavior: } \\
\hline Yes & .609 & .054 & .692 & .412 & .402 \\
\hline No & .391 & .946 & .308 & .588 & .598 \\
\hline \multicolumn{6}{|l|}{ Placement type: } \\
\hline Kinship foster care & .158 & .513 & .000 & .971 & .307 \\
\hline Nonrelative foster care & .312 & .333 & .706 & .000 & .361 \\
\hline \multicolumn{6}{|l|}{ Nonfamily or other } \\
\hline placement & .530 & .154 & .294 & .029 & .332 \\
\hline \multicolumn{6}{|l|}{ Placement stability:* } \\
\hline $0-1$ placement & .155 & .409 & .231 & .618 & .283 \\
\hline 2-4 placements & .388 & .449 & .529 & .353 & .430 \\
\hline 5 or more placements & .457 & .141 & .240 & .029 & .287 \\
\hline \multicolumn{6}{|l|}{ Runaway history: } \\
\hline Yes & .987 & .087 & .000 & .059 & .464 \\
\hline No & .013 & .913 & 1.00 & .941 & .536 \\
\hline
\end{tabular}

Note. - Problem behavior refers to respondents' experience of incarceration (juvenile detention) or expulsion from school. Nonrelative foster care refers to care provided in the homes of traditional, nonrelative foster parents; nonfamily or other placement includes such nonfamily settings as group homes, residential treatment centers, and independent living arrangements.

* Ordinal indicator; all others treated as nominal.

sample, is distinguished from other classes by having the lowest levels of grade retention and problem behaviors as well as the highest levels of employment experience. Youth in this group are most likely to reside in kinship foster care. The second most common placement arrangement is foster care without relatives. Respondents in class 2 are about half as likely as the full sample to reside in nonfamily placements. In addition, this group is characterized by a relatively stable placement history. Although the mode is $2-4$ placements, the remainder of the distribution is skewed toward one placement rather than five or more. Youth in this class demonstrate a rate of parenthood that is fairly typical for this sample. Finally, the reported likelihood of running away is substantially lower for class 2 respondents than for those in class 1 but remains somewhat higher than that reported for the other two groups.

Latent class 3.-The third class, which includes about 14 percent of the sample, is noteworthy for having the lowest reported rate of par- 
enthood and for having no reported cases of running away. However, youth in this class also report the highest rates of grade retention and problem behaviors. Class 3 youth live predominantly in traditional, nonrelative foster care. None lives in kinship foster care. Compared to youth in other classes, however, class 3 respondents report the second-highest rate of nonfamily placements. The majority of youth in this class report 2-4 placements; roughly equal percentages of respondents report either a greater or lesser number of placements.

Latent class 4.-The smallest class includes only about 5 percent of the sample. This profile is prominent for having the highest reported rate of parenthood, a high rate of grade retention, and the lowest reported rate of employment experience. In addition, this group is exceptional because almost all members live in kinship foster care, and most report that they are in their first placement. This profile is close to the sample average with respect to reported problem behavior, and the reported rate for running away is low.

\section{Validation of Classes}

Because LCA is used inductively in this analysis to generate distinct groupings, it is important to validate that the classes are differentiated on variables not used in the classification process. The aim is to determine whether the four classes obtained through LCA differ to a sufficient degree that the differences warrant representing the classes as distinctive groups. To the extent that the groups do differ in meaningful ways on other factors, such differences may provide additional insights into the nature of the classes. Table 3 presents all variables considered for validation purposes and details how the four classes contrast on these variables. The table also presents $F$-values for tests of independence, and results of Tukey's post hoc procedure are used to assess statistically significant pairwise comparisons. The validation variables are selected as indicators of several domains considered relevant in the transition to adulthood. These domains include demographic characteristics, education, out-of-home care experience, social network and social support, history of abuse or violent victimization, as well as mental health, alcohol, and substance abuse and delinquency. In order to verify that the empirically derived latent classes are not artifacts of the measures used in the LCA, the validation analyses include some variables similar to those used for classification. If the four classes truly are distinctive, a consistent pattern of differences should be observed among the groups on many, if not all, covariates. If statistical significance is observed on the majority of variables, the classification procedure has high validity. If statistical significance applies for roughly 5 percent of the variables, that is, if the number of associations is expected by chance, the claim of distinctive 
classes is dubious. Appendix table A1 provides information for the validation measures that are based on summary scales.

As shown in table 3, class 2 includes more females than males; males are more prevalent than females in class 3 . The class with the highest proportion of respondents who are parents (class 4 ) has an equal percentage of females and males. With respect to race, higher proportions of African American youth are found in class 4 and class 2 than in the other classes. Although youth from each state are represented in each class, respondents from Illinois are overrepresented in class 1, and respondents from Wisconsin contributed substantially more to class 3 than to class 1. Overall, the pattern on demographic factors is consistent with certain group differences noted earlier. For example, African American youth are more likely to be in kinship foster care than are other wards (Keller et al. 2001), and this correspondence is reflected in classes 2 and 4. However, the demographic comparisons reveal differences among the classes that are relatively modest. These results suggest that classification is not simply an artifact of differences in gender, race, or residence.

Class differences on several education variables generally validate the classification scheme, although some anomalies are observed. Consistent with their profile for high employment, low grade retention, and relatively stable placements, members of class 2 are the least likely to report ever being in a special education class or missing school due to changes in foster care. In addition, the youth in class 2 have the highest rate of school enrollment at the time of assessment and the highest mean score on the Wide Range Achievement Test-3 reading subscale (WRAT-3; Wilkinson 1993). Conversely, members of class 1 are the most likely to report placement in special education classes and missing school due to changes in foster care. Members of class 3 are similar to members of class 1 in having elevated rates for reported enrollment in special education classes and school disruptions due to foster care, although members of class 1 have higher rates on the latter variable. It thus is somewhat surprising that class 1 did not have an average rate of grade retention as high as that found in class 3 . Compared to peers in classes 1 and 3, respondents in class 4 report lower rates of special education and missing school due to changes in foster care. This suggests that the high rate of grade retention in class 4 may be attributable to other factors. The mean for WRAT scores for members of class 4 is markedly below the corresponding means for the other classes.

With respect to experiences in out-of-home care, members of class 1 are differentiated from those in other classes by being the least likely to report that they feel strongly or very strongly that they are lucky to be in foster care, rate their social workers as helpful, express satisfaction with their foster care experience, or anticipate relying on the foster care system for help after discharge. In general, this pattern of findings ac- 




466 


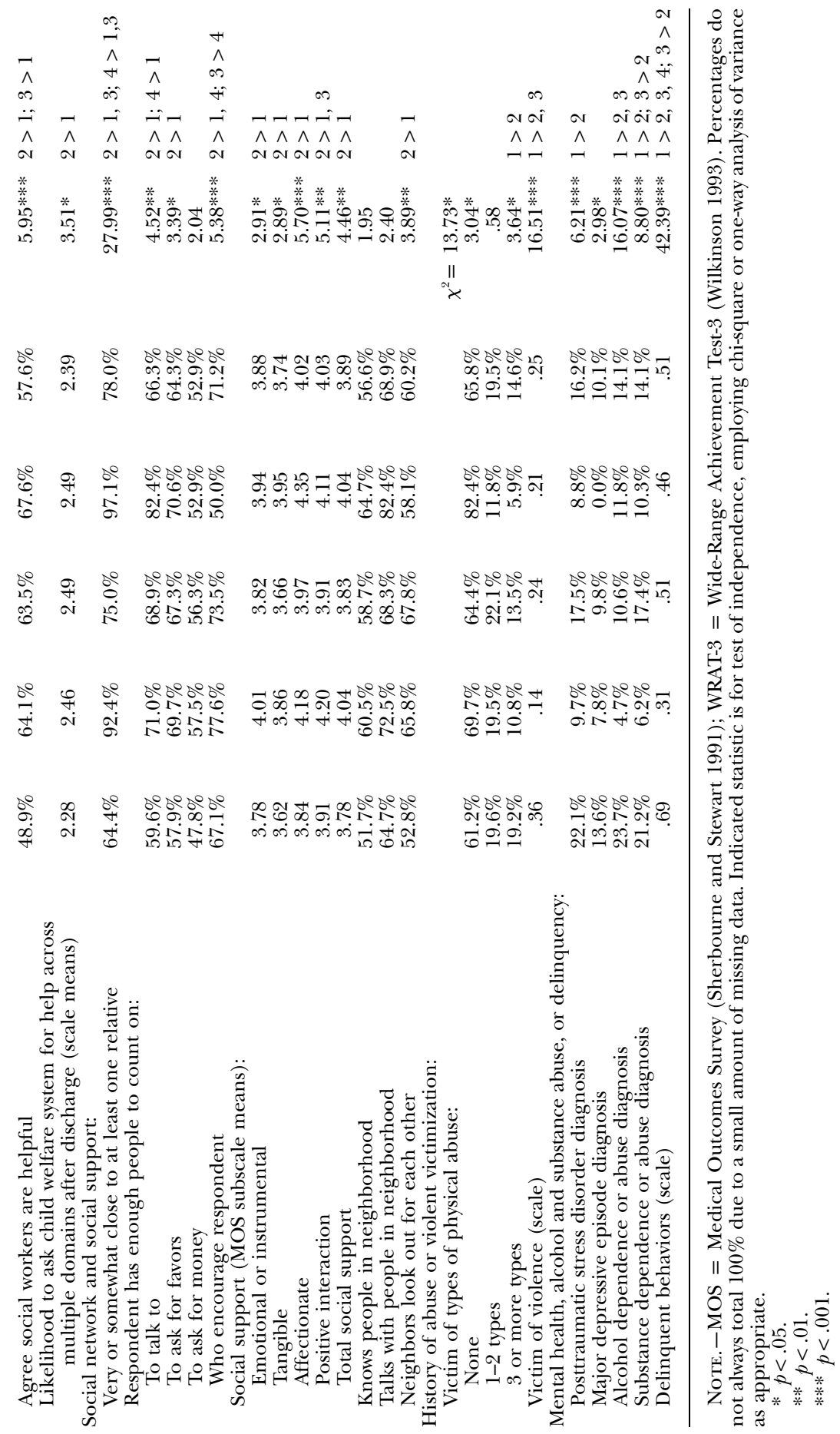

467 
cords with the class 1 profile, which indicates that members of class 1 are more likely than members of any other class to report nonfamily placements, placement instability, and a history of running away. Members of class 2 and class 3 report almost identical rates of feeling strongly or very strongly that they are lucky to be placed in foster care. Respondents in class 2 and class 3 also report highly similar rates of agreement that their social workers are helpful and that they are likely to ask the child welfare system for assistance in the future. Members of class 4 share a generally similar profile of regard for the child welfare system, although a lower percentage of class 4 respondents reports feeling strongly or very strongly that they are lucky to be in care. It is particularly noteworthy that members of class 3 report the highest rates of satisfaction with their foster care experience. Finally, it is interesting to observe that, despite the dissimilarities among the four classes, there are no statistically significant differences in the age at entry into care, in the likelihood of receiving independent living subsidies, or in various independent living services. There are two exceptions, however.

First, class 1 has the largest proportion of members receiving health services; class 2 has the lowest level of health service receipt. Second, members of class 3 are the least likely to report receiving educational services; members of class 2 are most likely to report using these services. The fact that members of class 3 and class 2 have the highest and lowest rates of grade retention, respectively, suggests the need for further investigation of issues related to access and effectiveness of educational services.

Differences on indicators of social network and social support also are analyzed. In general, members of class 1 are least likely to report that they are close to at least one relative; members of classes 2 and 4 are very likely to report feeling close to at least one relative. Youth in classes 2 and 4 also report relatively high rates of having enough people to talk to and to ask for favors; these rates are lower for members of class 1 . However, respondents in class 4 are the least likely to report having enough people who provide encouragement to them. In general, the responses of members of class 3 place them in the range between classes 1 and 2 on these measures of social network, but the values for class 3 more closely resemble those of class 2 . Mean responses on the Medical Outcomes Survey social support scales (MOS; Sherbourne and Stewart 1991) indicate that there are class differences for emotional or instrumental support, tangible support, affectionate support, positive interaction, and total support. Members of class 1 typically report the lowest means on these social support scales, although the means for members of class 3 are often comparably low. Mean levels of social support are consistently higher for members of classes 2 and 4 than for classes 1 and 3, but only contrasts between classes 1 and 2 are statistically significant due to the different sizes of the groups. On questions as- 
sessing social connectedness to neighbors, members of class 1 regularly report the lowest rates on indicators of ties with people in the neighborhood. This pattern of findings is consistent with the high levels of kinship foster care and placement stability reported by members of classes 2 and 4, as well as with the high rate of nonfamily placement and lack of placement stability reported by members of class 1 .

Statistically significant variations in levels of abuse and violent victimization are observed across the different latent classes. A count of items reflecting different types of physical abuse suggests that youth in class 1 are more likely to report some type of physical abuse and more types of abuse than are youth in any other class. In contrast, youth in class 4 are the least likely to report any physical abuse. Class 1 also has the highest mean for a scale on which respondents report experiences of being a victim of violence.

Comparisons are made among the classes on several diagnoses assessed with the Composite International Diagnostic Interview (CIDI; WHO 1997). Youth in class 1 are the most likely to have diagnoses of posttraumatic stress disorder, a major depressive episode, alcohol dependence or abuse, and substance dependence or abuse. Although members of class 3 have elevated rates for some diagnoses, particularly those of substance abuse and dependence, the rates for class 1 often are more than double those observed for classes 2 and 4 . In addition, the mean for a self-reported index of recent delinquent behaviors is higher for members of class 1 than for members of any other class.

\section{Discussion}

The purpose of the present study is to investigate heterogeneity among youth who are on the verge of exiting the child welfare system and making the transition to independent living. The application of empirical person-oriented methods identifies four subpopulations that exhibit distinctive profiles, which are based on selected indicators of their foster care experience and preparation for adjustment to adult functioning. These profiles identify groups of individuals who systematically differ in their past experiences, current circumstances, and, perhaps, future prospects. In other words, the particular patterns reflected in the profiles indicate different pathways taken up to the point of exiting the child welfare system. Class membership thus may forecast trajectories during the transition to independence. Understanding these diverse pathways can highlight the needs and challenges of youth aging out of foster care, as well as the opportunities available to them. Such an understanding can suggest how policies and practices might best prepare groups of adolescents contending with very different circumstances as they leave the child welfare system.

Several long-standing program and service approaches are specifically 
designed to help prepare adolescents in state care for adult living. These include training foster caregivers to promote the development of independent living skills, offering courses in life-skills training, establishing mentoring relationships and social networks, facilitating contact with birth families, providing postsecondary scholarships, subsidizing living expenses, and operating supervised transitional housing facilities (Barth 1986; Maluccio, Krieger, and Pine 1990; Mech and Rycraft 1995; Massinga and Pecora 2004). Recent legislation, most prominently the Foster Care Independence Act of 1999 (U.S. Public Law 106-169), which created the Chafee Foster Care Independence Program, provides new federal guidelines and additional resources for states. Primary goals of this legislation are to increase the provision of services and to expand eligibility, enabling youth to continue receiving services until they reach age 21 (Collins 2004). This legislation attempts to promote youth development, permanency, and self-sufficiency by granting states considerable latitude to address the education, employment, and personal and emotional well-being of wards between the ages of 18 and 21. Assistance can take the form of education and training programs, mentoring, youth development programs, financial subsidies, housing, counseling, health services, and mental health services. It is possible to interpret key characteristics of the four latent classes within this frame of reference, discussing the potential implications of those characteristics for policy and practice within the context of services provided through the child welfare system.

\section{Distressed and Disconnected}

Young people in class 1 seem most likely to experience difficulties in the transition to adulthood, and their condition is accordingly described as distressed and disconnected. This profile, which represents more respondents than any other class identified in the study, suggests a troubled history in the child welfare system. Compared to respondents in other classes, these youth are more likely to have multiple placements, episodes of running away, and placement in nonfamily settings (e.g., group care). Placement in nonfamily settings usually is reserved for youth who have been unmanageable in family care settings and who need intensive supervision. Consistent with this pattern, youth in class 1 give evidence of psychosocial and adjustment difficulties. Compared with members of other classes, they report higher rates of being a victim of physical abuse, higher rates of being a victim of violence, higher prevalence of mental health and substance use diagnoses, higher rates of enrollment in special education classes, and higher levels of delinquent behaviors, as well as high rates of other problem behaviors (i.e., those incurring such formal sanctions as expulsion or incarceration). Youth in class 1 also show signs of social alienation; they are less likely 
than youth in other classes to report feeling very or somewhat close to at least one relative or having enough people who can be counted on to provide the four measured types of assistance. Class 1 youth are also less likely to report receiving various forms of social support and having personal connections within their neighborhoods. Finally, these youth are less likely than those in other classes to report that they are strongly or very strongly satisfied with their care experience in the child welfare system, that social workers are helpful, or that they will seek help from the child welfare system after discharge from it.

Overall, the picture that emerges for this class is one of troubled adolescents who are socially disconnected from adults and who are also at odds with formal systems of support. Consequently, youth in class 1 pose many challenges to the foster care system. Because members of this class appear to be poorly equipped for the expectations of adulthood, it seems particularly important to address the needs of these young people while they are still in care. However, the instability of their placements, their tendency to run from care, and their high rate of problem behaviors all suggest that the child welfare system has had difficulties creating for them stable, supportive, and therapeutic living situations in which they can begin to prepare for adulthood. Unless fundamental obstacles to social adjustment are resolved first, it seems unlikely that traditional independent living services will be beneficial for these youth during the transition to independence. The likelihood of negative outcomes in the transition to adulthood is greater for adolescents with histories of institutionalization and psychiatric difficulties than for those without such experiences (Vander Stoep et al. 2000). High rates of mental health and substance-related diagnoses among members of this class therefore suggest the need for a comprehensive system of care to support their development (Davis 2003). Furthermore, youth in this class may have few options for assistance other than reliance on the child welfare system; previous research indicates that adolescents in group care placements are less likely to successfully emancipate to independent living or return to family-like settings (Courtney and Barth 1996). In short, many of these young people are likely to have a continuing need for extensive support and supervision, but they may be resistant to such help.

\section{Competent and Connected}

By most indications, youth in class 2 seem poised to make steady progress in their development toward adulthood. This second-largest group can be described as competent and connected. Most members of this class have reasonably few placement changes, and their placements are often with kin. This class is above average on rates of reporting satisfaction with the foster care experience (e.g., lucky to be in care, view social 
workers as helpful, overall satisfaction). Likewise, members of class 2 are likely to indicate feeling close to at least one relative, having people to count on for several types of help, receiving various types of social support, and having personal connections in their neighborhoods. In general, these youth are unlikely to exhibit problem behaviors, delinquent behaviors, or mental health and substance-related disorders. Furthermore, this profile gives evidence of solid performance in the areas of education and employment. Of all respondents in the sample, these youth are the most likely to report that they never experienced grade retention, are enrolled in school at the time of the interview, and have work experience.

Although the class 2 profile provides reason for optimism, these young people may face ongoing struggles to overcome adversity. For example, qualitative studies of high-achieving former foster youth note that such youth encounter a range of obstacles in pursuing higher education (Martin and Jackson 2002; Hines, Merdinger, and Wyatt 2005). Such obstacles may include feelings of stigma and low expectations associated with their foster care status. Youth also may experience sadness and guilt in comparing their success to that of other family members. Obstacles also may come in the form of such practical concerns as a lack of resources for school supplies and for housing during school breaks. Former foster youth who achieve educational and career goals emphasize that consistent encouragement from a mentor, foster parent, or social worker throughout college was instrumental in their success (Martin and Jackson 2002; Hines et al. 2005). If they receive continuing support of programs and services that prepare them for independent living, the majority of young people in class 2 seem relatively well positioned to make the transition to adulthood. These youth are probably the most likely to benefit from opportunities and services that enable them to nurture their talents, form mentoring relationships, engage in youth development programs, attend college, and participate in vocational training (Gilligan 1999).

Approximately 80 percent of the sample is categorized into either the distressed and disconnected group or the competent and connected group. It follows that the child welfare system must contend with a large number of youth whose behavior and antipathy toward the system pose difficulties. These youth likely will require a range of relatively intensive supports for the foreseeable future. In addition, child welfare policy and practice must accommodate a large number of youth who present a more hopeful profile. These youth will need to develop skills for independent living and also will need continuing support in the transition to adulthood, although support of a very different nature than that needed by youth in the first group. Thus, the study identifies two large but clearly distinct service populations. However, the remaining 
two classes suggest that the child welfare system requires even greater flexibility to meet the needs of all youth aging out of care.

\section{Struggling but Staying}

Class 3 seems to represent a group of youth who are approaching the transition to independence with numerous challenges but, compared to class 1 respondents, have possibly more constructive engagement in the child welfare system. Youth in this third class might be characterized as struggling but staying. They are more likely than youth in any other class to experience grade retention, and they also indicate a high rate of enrollment in special education classes. In addition, they report the highest rates of problem behaviors that result in expulsion or incarceration. However, these youth, who typically have nonrelative foster placements, seem somewhat more amenable than youth in class 1 to intervention by the child welfare system. They are the most likely to report feeling lucky for placement in out-of-home care and to report satisfaction with their foster care experience. Most notably, they stay with their caregivers; none reported running away from a placement. In addition, relative to the rest of the sample, they indicate a high likelihood of asking the child welfare system for continuing support in numerous life domains after they are discharged from the system.

These patterns suggest a group of youth who may be receptive to the type of intensive services required to address their problem behaviors and difficulties in educational attainment. Young people in this group appear more open to using the child welfare system to meet their needs, and they expect to rely on the system in the future. If they are able to stay connected with the child welfare system and their foster care providers during the transition to adulthood, they may be better able than the distressed and disconnected group to take advantage of life-skills training and transitional living services. Although there may be selection effects, former foster youth who maintain relationships to siblings, foster parents, or biological parents tend to fare better than those without continuing ties (Kerman, Wildfire, and Barth 2002). However, society's strong emphasis on achieving self-sufficiency and independence may cause some foster parents and caseworkers to consider the need for continued assistance as a sign of the adolescent's weakness or irresponsibility (Iglehart 1994). Recognizing that the abilities to ask for help and to utilize external resources are central to healthy development throughout the life course, some authors promote the concept of interdependent living as a more realistic goal than independent living for many youth transitioning out of foster care (Propp, Ortega, and NewHeart 2003). In light of this perspective, it may be shortsighted to deprive young people in class 3 of the ongoing support they may seek. Yet most states, including two of the three states in this study, routinely 
relinquish their responsibility for young people in out-of-home care when the youths turn 18 years old.

\section{Hindered and Homebound}

Class 4, which represents a small fraction of the sample (5 percent), includes another subpopulation of youth who could have a problematic transition to adulthood. They may be described as hindered and homebound. On the one hand, the majority of these youth are in their first foster placement, and nearly all live with relatives. Perhaps as a result of this placement stability, they tend to report close relations with relatives, connections with their neighborhoods, and relatively high levels of social support. On the other hand, their profile is distinguished by a high rate of grade retention and a very low rate of any prior employment. These characteristics suggest that their transition to adulthood could be hindered by lack of preparation for self-sufficiency. The relatively poor record in terms of education and employment coincides with the fact that they have the lowest mean reading scores of all classes and with a relatively low likelihood of encouragement from their social network. Furthermore, compared with other classes, this class is exceptional for a much higher rate of parenthood at 17 years of age. Although starting a family is a traditional marker of becoming an adult, parenthood at this early age could be considered an off-time transition that imposes time and financial constraints (Brooks-Gunn and Chase-Lansdale 1995). Such constraints may affect opportunities for education, employment, housing, and relationships. Overall, it seems doubtful that these youth will be able to support themselves or their children during the transition to adulthood, but they may continue to rely on support from their families. However, the long-term viability of this support may be uncertain because, compared to nonrelative foster parents, kinship caregivers tend to be older, less educated, more economically disadvantaged, and more likely to be single heads of households (Berrick, Barth, and Needell 1994). Moreover, some research suggests that multigenerational coresidence may be detrimental to the development of parenting behaviors and competence among adolescent mothers (Chase-Lansdale, Brooks-Gunn, and Zamsky 1994).

Class 4 may represent a relatively small and atypical subset of youth living in kinship foster care. A large majority of study participants living in kinship foster care are members of class 2, the competent and connected group. This is consistent with earlier research finding that youth in kinship care exhibit more competencies and fewer problem behaviors than their counterparts in nonrelative care (Keller et al. 2001). Further research may reveal explanations for the differences observed between the hindered and homebound profile and that of their competent and connected counterparts. The current analysis suggests that one such explanation may be tied to variation in caregiver encouragement to pursue 
education and obtain work experience. The apparent lack of preparation for adulthood among members of class 4 may be partially mitigated if their extended families are willing and able to continue providing for them. Because these youth have close family ties and parenting responsibilities, the child welfare system may need to consider the nature of educational and employment expectations for these youth, as well as the degree of emphasis placed on moving them toward greater self-sufficiency.

\section{Conclusion}

This article identifies four distinctive subpopulations of adolescents aging out of the child welfare system. The use of person-oriented analyses enhances the relevance and applicability of the findings for professionals working with young people in out-of-home care. The holistic, personoriented approach is consistent with social work's emphasis on interactions among multiple systemic factors (Kemp, Whittaker, and Tracy 1997). In addition, this approach corresponds to assessment and caseplanning procedures employed by child welfare workers and other clinicians working with adolescents (Gray 2001; Merrell 2003; Surko et al. 2005). Just as workers attempt to conduct comprehensive assessments of the circumstances of individuals, the study draws on measures that represent multiple domains of the adolescent's experience. Just as workers attempt to condense extensive information into a coherent framework for interpreting each situation and comparing it to previously encountered cases, the analyses identify meaningful subgroups of individuals who share similar characteristics. These parallels with the clinical assessment process should make the results of the study easily interpretable and easily transferable to practical application.

However, the findings reported here should be interpreted cautiously. Readers should consider both the strengths and limitations of the study. For example, the study is not based on a national sample, and the results cannot generalize to the widest population of youth aging out of care. Yet the large sample is representative of youth leaving care in three midwestern states (Illinois, Iowa, and Wisconsin) with diverse populations. These states have major urban centers as well as suburban and rural communities. Another caveat regarding the sample involves the exclusion of youth who were incarcerated or receiving inpatient treatment. The status of each individual with respect to incarceration or inpatient treatment may change over time, and a limitation of the study is the use of cross-sectional data that reflect conditions at a single point in time. However, the sample is a specially selected age-cohort assessed in the year before exiting the child welfare system. Thus, it seems reasonable to assume that status at the time of the baseline interview is relevant to sample members' preparation for independent living. In addition, a distinction can be made between a study of all youth in the 
child welfare system and a study of youth exiting that system. This study focuses on youth who are about to leave state custody and take responsibility for themselves.

Several of the variables used as indicators for the LCA classification procedure are simple dichotomous items based on responses to single survey questions. As noted earlier, though, the practical relevance of the study is enhanced by using indicators that should be readily available in case files or to those familiar with the individual case. Another potential criticism is that the indicators may not accurately reflect circumstances at the point of transition because the indicators often summarize cumulative experience (e.g., grade retention, placement stability). However, social processes that sort individuals for opportunities in higher education, employment, housing, and family formation often involve selection based on past history, so these indicators reflect a record that may affect opportunities during the transition to adulthood.

Although it is legitimate to debate the choice of these indicators over other possible measures, the findings from the comparison of the four classes on related variables suggest that similar profiles may emerge if other indicators in the same domains are used as the basis for classification. Many of the variables used in these comparisons are sophisticated and detailed research measures. Others refer to status at or near the time of the interview (e.g., currently enrolled in school). Most important, the effort to validate the groups yielded a pattern of results indicating each class is distinctive and conceptually coherent. In other words, the associations of variables within groups and the differences among groups have a consistent logic as well as face validity. This point also supports the choice of a four-class model over a three-class solution. The essential distinction between the three-class and four-class solutions is the presence of the struggling but staying group. In the three-class model, individuals in this category are assigned to groups resembling those here described as distressed and disconnected (class 1) and competent and connected (class 2). Yet the findings suggest that youth designated struggling but staying differ substantively in their circumstances and needs.

Nevertheless, the use of person-oriented methods requires judgment in determining the preferred solution. The results and their interpretations may therefore be called into question. Because the classes are derived through an empirically driven inductive process, replication of the findings with other samples will enhance their credibility. Likewise, the profiles described in this study will have greater utility if prospective studies show they actually do forecast very different probabilities for successful functioning in adulthood. It would be inappropriate, furthermore, to reify the four categories of youth aging out of care and the descriptive labels ascribed to those categories in a way that may contribute to stereotyping. This risk is inherent in a categorization that is based on a few salient indices, yet the systematic use of empirical data, as done in these analyses, 
actually may counteract stereotypes. Research indicates that stereotypes tend to arise from selective attention to information that is consistent with preconceived notions stemming from biases and naive theories (Wittenbrink, Hilton, and Gist 1998). The categories derived here stem from statistical procedures applied objectively to data.

Several additional points must be emphasized. First, the profiles are probabilistic, and considerable intraclass heterogeneity remains. Second, the analysis and interpretation of results highlight salient differences among classes. A variable may be used to characterize a particular class relative to others, but that noteworthy feature certainly does not apply universally to all members of the class. Third, the classes represent categorization at a single point in time, but individuals are not static. As noted at the outset, the transition to adulthood is a period of great change in developmental pathways.

Finally, it is important to recognize that the current study does not consider causal relationships among the factors used to identify and define the subpopulations. Instead, it empirically determines which conditions are likely to co-occur. Observing particular configurations of cooccurring factors is a valuable step in generating explanatory and predictive hypotheses, but further research is necessary to better understand how the factors interact in the transition to adulthood. Certain multidomain profiles may be observed because the indicators reflect different manifestations of an overall capacity for adult functioning, because there is a developmental chain reaction across domains (e.g., problem behavior leads to school failure, which leads to unemployment), or because some earlier individual or environmental factors are so powerful as to have separate, direct effects in each domain. Qualitative research with samples that represent each identified subpopulation could serve as a next step in suggesting the underlying processes that contribute to distinctive pathways as youth age out of care.

Although identification of distinctive subpopulations may stimulate new avenues for research on developmental processes, it also has implications for child welfare policy and practice. In an increasingly complex and competitive society, many young people are becoming more heavily reliant upon continuing family support as they pursue extended education and attempt to become established in early adult roles (Arnett 2000). Young people in the custody of the state tend to face this same transition with greater challenges and fewer resources than most of their peers (Collins 2001). Recent legislation encourages the child welfare system to explore how older adolescents in out-of-home care could benefit from continuing support and intervention (Collins 2004). The findings of this study suggest the possibility of tailoring ongoing support to the particular needs and circumstances of distinctive subpopulations of youth who are leaving care and embarking on the transition to adulthood. 


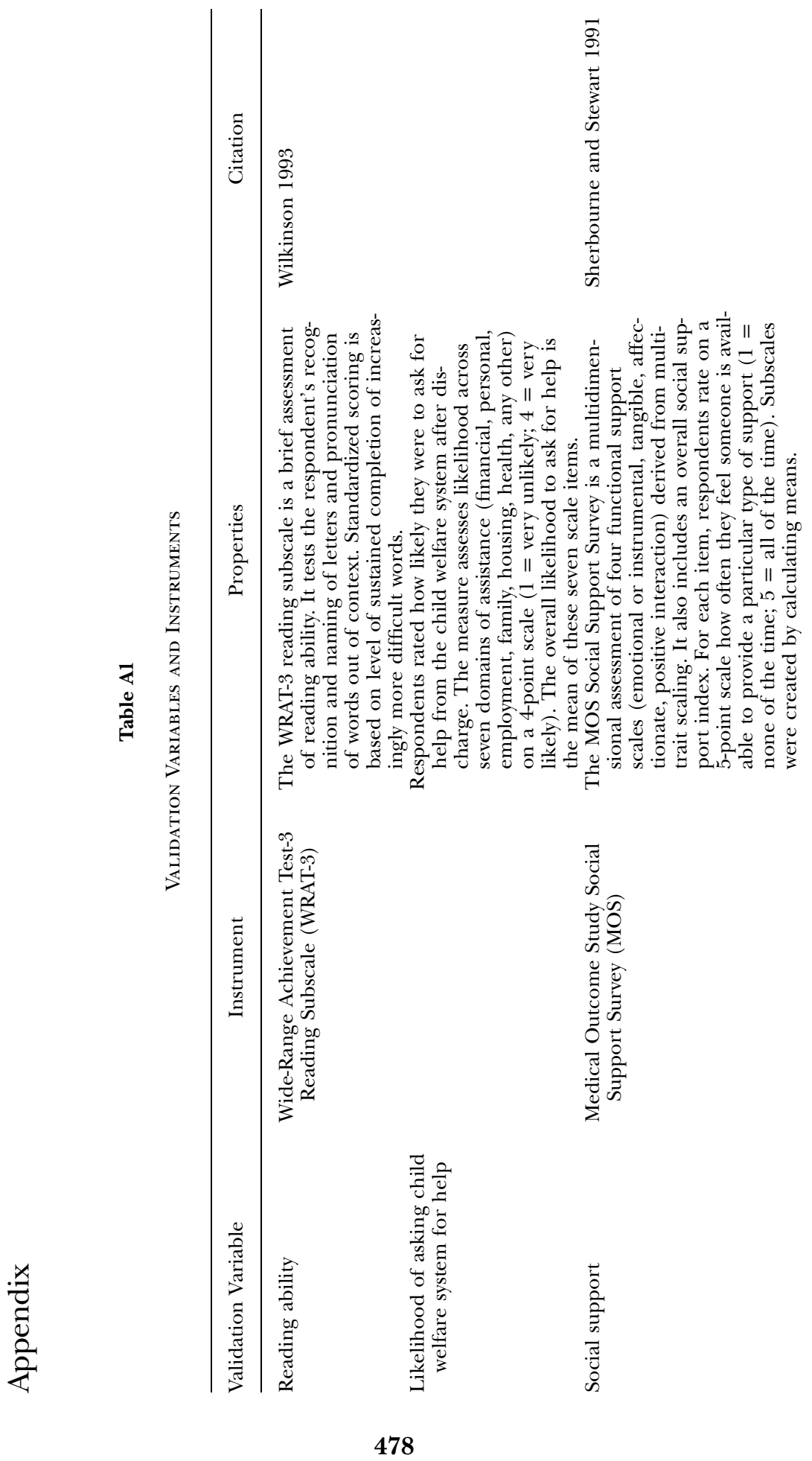




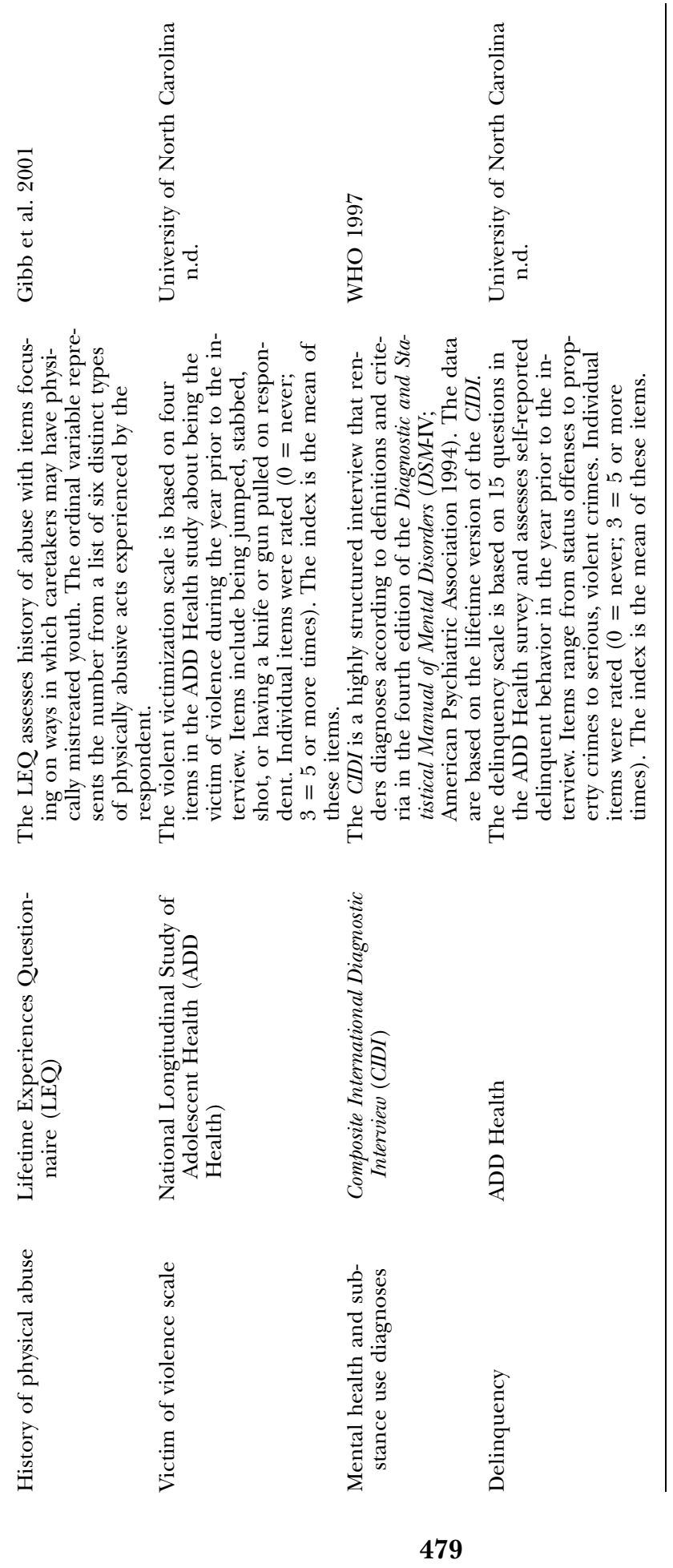




\section{References}

Adam, Emma K. 2004. "Beyond Quality: Parental and Residential Stability and Children's Adjustment." Current Directions in Psychological Science 13 (5): 210-13.

Allen, Joseph P., and Deborah Land. 1999. "Attachment in Adolescence." 319-35 in Hand book of Attachment: Theory, Research, and Clinical Applications, edited by Jude Cassidy and Phillip R. Shaver. New York: Guilford.

American Psychiatric Association. 1994. Diagnostic and Statistical Manual of MentalDisorders. 4th ed. Washington, DC: American Psychiatric Association.

$\rightarrow$ Arnett, Jeffrey J. 2000. "Emerging Adulthood: A Theory of Development from the Late Teens through the Twenties." American Psychologist 55 (5): 469-80.

Barth, Richard P. 1986. "Emancipation Services for Adolescents in Foster Care." Social Work 31 (3): 165-71.

$\rightarrow$ 1990. "On Their Own: The Experiences of Youth after Foster Care." Child and Adolescent Social Work Journal 7 (5): 419-40.

Bell, Kathy L., Joseph P. Allen, Stuart T. Hauser, and Thomas G. O’Connor. 1996. "Family Factors and Young Adult Transitions: Educational Attainment and Occupational Prestige." 345-66 in Transitions through Adolescence: Interpersonal Domains and Context, edited by Julia A. Graber, Jeanne Brooks-Gunn, and Anne C. Petersen. Hillsdale, NJ: Erlbaum.

$\rightarrow$ Bergman, Lars R., and David Magnusson. 1997. "A Person-Oriented Approach in Research on Developmental Psychopathology." Development and Psychopathology 9 (2): 291-319.

Bergman, Lars R., David Magnusson, and Bassam M. El-Khouri. 2003. Studying Individual Development in an Interindividual Context: A Person-Oriented Approach. Vol. 4 in Paths through Life, edited by David Magnusson. Mahwah, NJ: Erlbaum.

$\rightarrow$ Berrick, Jill Duerr, Richard P. Barth, and Barbara Needell. 1994. "A Comparison of Kinship Foster Homes and Foster Family Homes: Implications for Kinship Foster Care as Family Preservation." Children and Youth Services Review 16 (1-2): 33-63.

Bronfenbrenner, Urie, and Pamela A. Morris. 1998. "The Ecology of Developmental Processes." 993-1028 in Theoretical Models of Human Development, edited by Richard M. Lerner. Vol. 1 in Handbook of Child Psychology, 5th ed., edited by William Damon. New York: Wiley.

Brooks-Gunn, Jeanne, and P. Lindsay Chase-Lansdale. 1995. "Adolescent Parenthood." 113-49 in Status and Social Conditions of Parenting. Vol. 3 in Handbook of Parenting, edited by Marc H. Bornstein. Mahwah, NJ: Erlbaum.

$\rightarrow$ Buehler, Cheryl, John G. Orme, James Post, and David A. Patterson. 2000. "The LongTerm Correlates of Family Foster Care." Children and Youth Services Review 22 (8): $595-625$.

$\rightarrow$ Chase-Lansdale, P. Lindsay, Jeanne Brooks-Gunn, and Elise S. Zamsky. 1994. "Young African-American Multigenerational Families in Poverty: Quality of Mothering and Grandmothering." Child Development 65 (2): 373-93.

Cicchetti, Dante, and Donald J. Cohen. 1995. "Perspectives on Developmental Psychopathology." 3-20 in Theory and Methods. Vol. 1 in Developmental Psychopathology, edited by Dante Cicchetti and Donald J. Cohen. New York: Wiley.

$\rightarrow$ Cicchetti, Dante, and Fred A. Rogosch. 2002. "A Developmental Psychopathology Perspective on Adolescence." Journal of Consulting and Clinical Psychology 70 (1): 6-20.

$\rightarrow$ Cohen, Patricia, Stephanie Kasen, Henian Chen, Claudia Hartmark, and Kathy Gordon. 2003. "Variations in Patterns of Developmental Transitions in the Emerging Adulthood Period." Developmental Psychology 39 (4): 657-69.

$\rightarrow$ Coley, Rebekah Levine, and P. Lindsay Chase-Lansdale. 1998. "Adolescent Pregnancy and Parenthood: Recent Evidence and Future Directions." American Psychologist 53 (2): 152-66.

$\rightarrow$ Collins, Mary Elizabeth. 2001. "Transition to Adulthood for Vulnerable Youths: A Review of Research and Implications for Policy." Social Service Review 75 (2): 271-91.

$\rightarrow-$ 2004. "Enhancing Services to Youths Leaving Foster Care: Analysis of Recent Legislation and Its Potential Impact." Children and Youth Services Review 26 (11): $1051-65$.

Cook, Ronna, Esther Fleishman, and Virginia Grimes. 1991. "A National Evaluation of Title IV-E Foster Care Independent Living Programs for Youth: Phase 2; Final Report.” 
Report to the U.S. Department of Health and Human Services, Administration for Children, Youth and Families (contract no. 105-87-1608). WESTAT, Rockville, MD.

Courtney, Mark E., and Richard P. Barth. 1996. "Pathways of Older Adolescents out of Foster Care: Implications for Independent Living Services.” Social Work 41 (1): 75-83.

Courtney, Mark E., Amy Dworsky, Gretchen Ruth, Tom Keller, Judy Havlicek, and Noel S. Bost. 2005. "Midwest Evaluation of the Adult Functioning of Former Foster Youth: Outcomes at Age 19." Working paper CS-116. Chapin Hall Center for Children at the University of Chicago.

Courtney, Mark E., Irving Piliavin, Andrew Grogan-Kaylor, and Ande Nesmith. 2001. "Foster Youth Transitions to Adulthood: A Longitudinal View of Youth Leaving Care." Child Welfare 80 (6): 685-717.

Courtney, Mark E., Sherri Terao, and Noel S. Bost. 2004. "Midwest Evaluation of the Adult Functioning of Former Foster Youth: Conditions of Youth Preparing to Leave State Care." Working paper CS-97. Chapin Hall Center for Children at the University of Chicago.

Csikszentmihalyi, Mihaly, and Barbara L. Schneider. 2000. Becoming Adult: How Teenagers Prepare for the World of Work. New York: Basic.

$\rightarrow$ Davis, Maryann. 2003. "Addressing the Needs of Youth in Transition to Adulthood." Administration and Policy in Mental Health 30 (6): 495-509.

Elder, Glen H., Jr. 1998. "The Life Course and Human Development." 939-91 in Theoretical Models of Human Development, edited by Richard M. Lerner. Vol. 1 in Handbook of Child Psychology, 5th ed., edited by William Damon. New York: Wiley.

Fein, Edith, Anthony N. Maluccio, and Miriam P. Kluger. 1990. No More Partings: An Examination of Long-Term Foster Family Care. Washington, DC: Child Welfare League of America.

Foster, E. Michael, and Elizabeth J. Gifford. 2005. "The Transition to Adulthood for Youth Leaving Public Systems: Challenges to Policies and Research.” 501-33 in On the Frontier of Adulthood: Theory, Research, and Public Policy, edited by Richard A. Settersten Jr., Frank F. Furstenberg Jr., and Rubén G. Rumbaut. Chicago: University of Chicago Press.

$\rightarrow$ George, Linda K. 1993. "Sociological Perspectives on Life Transitions." Annual Review of Sociology 19:353-73.

$\rightarrow$ Gibb, Brandon E., Lauren B. Alloy, Lyn Y. Abramson, Donna T. Rose, Wayne G. Whitehouse, Patricia Donovan, Michael E. Hogan, Judith Cronholm, and Sandra Tierney. 2001. "History of Childhood Maltreatment, Negative Cognitive Styles, and Episodes of Depression in Adulthood." Cognitive Therapy and Research 25 (4): 425-46.

$\rightarrow$ Gibson, W. A. 1959. "Three Multivariate Models: Factor Analysis, Latent Structure Analysis, and Latent Profile Analysis." Psychometrika 24 (3): 229-52.

$\rightarrow$ Gilligan, Robbie. 1999. "Enhancing the Resilience of Children and Young People in Public Care by Mentoring Their Talents and Interests." Child and Family Social Work 4 (3): 187-96.

$\rightarrow$ Goldscheider, Frances K., and Calvin Goldscheider. 1998. "The Effects of Childhood Family Structure on Leaving and Returning Home." Journal of Marriage and the Family 60 (3): $745-56$.

Gore, Susan, Robert Aseltine Jr., Mary Ellen Colten, and Bin Lin. 1997. "Life after High School: Development, Stress, and Well-Being." 197-214 in Stress and Adversity over the Life Course: Trajectories and Turning Points, edited by Ian H. Gotlib and Blair Wheaton. New York: Cambridge University Press.

$\rightarrow$ Gray, Jenny. 2001. "The Framework for the Assessment of Children in Need and Their Families." Child Psychology and Psychiatry Review 6 (1): 4-10.

$\rightarrow$ Harden, Brenda Jones. 2004. "Safety and Stability for Foster Children: A Developmental Perspective." Future of Children 14 (1): 31-47.

Henry, Gary T. 1990. Practical Sampling. Applied Social Research Methods series, edited by Leonard Bickman and Debra J. Rog. Newbury Park, CA: Sage.

$\rightarrow$ Hines, Alice M., Joan Merdinger, and Paige Wyatt. 2005. "Former Foster Youth Attending College: Resilience and the Transition to Young Adulthood." American Journal of Orthopsychiatry 75 (3): 381-94.

Iglehart, Alfreda P. 1994. "Adolescents in Foster Care: Predicting Readiness for Independent Living." Children and Youth Services Review 16 (3-4): 159-69.

$\rightarrow$ Keller, Thomas E., Richard F. Catalano Jr., Kevin P. Haggerty, and Charles B. Fleming. 
2002. "Parent Figure Transitions and Delinquency and Drug Use among Early Adolescent Children of Substance Abusers." American Journal of Drug and Alcohol Abuse 28 (3): 399-427.

$\rightarrow$ Keller, Thomas E., Kathleen Wetherbee, Nicole S. Le Prohn, Vincent Payne, Kelly Sim, and Elena R. Lamont. 2001. "Competencies and Problem Behaviors of Children in Family Foster Care: Variations by Kinship Placement Status and Race.” Children and Youth Services Review 23 (12): 915-40.

Kemp, Susan P., James K. Whittaker, and Elizabeth M. Tracy. 1997. Person-Environment Practice: The Social Ecology of Interpersonal Helping. New York: Aldine de Gruyter.

$\rightarrow$ Kerman, Benjamin, Judith Wildfire, and Richard P. Barth. 2002. "Outcomes for Young Adults Who Experienced Foster Care." Children and Youth Services Review 24 (5): 319-44.

$\rightarrow$ Leventhal, Tama, Julia A. Graber, and Jeanne Brooks-Gunn. 2001. "Adolescent Transitions to Young Adulthood: Antecedents, Correlates, and Consequences of Adolescent Employment." Journal of Research on Adolescence 11 (3): 297-323.

Magidson, Jay, and Jeroen K. Vermunt. 2004. "Latent Class Models." 175-98 in The Sage Handbook of Quantitative Methodology for the Social Sciences, edited by David Kaplan. Thousand Oaks, CA: Sage.

Magnusson, David. 1995. "Individual Development: A Holistic, Integrated Model." 19-60 in Examining Lives in Context: Perspectives on the Ecology of Human Development, edited by Phyllis Moen, Glen H. Elder Jr., and Kurt Lüscher. Washington, DC: American Psychological Association.

- 1998. "The Logic and Implications of a Person-Oriented Approach." 33-64 in Methods and Models for Studying the Individual, edited by Robert B. Cairns, Lars R. Bergman, and Jerome Kagan. Thousand Oaks, CA: Sage.

Maluccio, Anthony N., Robin Krieger, and Barbara A. Pine, eds. 1990. Preparing Adolescents for Life after Foster Care: The Central Role of Foster Parents. Washington, DC: Child Welfare League of America.

$\rightarrow$ Martin, Pearl Y., and Sonia Jackson. 2002. "Educational Success for Children in Public Care: Advice from a Group of High Achievers." Child and Family Social Work 7 (2): 121-30.

$\rightarrow$ Massinga, Ruth, and Peter J. Pecora. 2004. "Providing Better Opportunities for Older Children in the Child Welfare System." Future of Children 14 (1): 151-73.

$\rightarrow$ Masten, Ann S., Keith B. Burt, Glenn I. Roisman, Jelena Obradovic, Jeffrey D. Long, and Auke Tellegen. 2004. "Resources and Resilience in the Transition to Adulthood: Continuity and Change." Development and Psychopathology 16 (4): 1071-94.

Maughan, Barbara, and Lorna Champion. 1990. "Risk and Protective Factors in the Transition to Young Adulthood." 296-331 in Successful Aging: Perspectives from the Behavioral Sciences, edited by Paul B. Baltes and Margaret M. Baltes. New York: Cambridge University Press.

McCutcheon, Allan L. 1987. Latent Class Analysis. Quantitative Applications in the Social Sciences, Sage University Paper no. 07-064. Newbury Park, CA: Sage.

McMillen, J. Curtis, and Jayne Tucker. 1999. "The Status of Older Adolescents at Exit from Out-of-Home Care." Child Welfare 78 (3): 339-60.

Mech, Edmund V. 2003. Uncertain Futures: Foster Youth in Transition to Adulthood. Washington, DC: Child Welfare League of America.

Mech, Edmund V., and Joan R. Rycraft, eds. 1995. Preparing Foster Youths for Adult Living: Proceedings of an Invitational Research Conference. Washington, DC: Child Welfare League of America.

Merrell, Kenneth W. 2003. Behavioral, Social, and Emotional Assessment of Children and Adolescents. 2nd ed. Mahwah, NJ: Erlbaum.

Mortimer, Jeylan T., Carolyn Harley, and Pamela J. Aronson. 1999. "How Do Prior Experiences in the Workplace Set the Stage for Transitions to Adulthood?" 131-59 in Transitions to Adulthood in a Changing Economy: No Work, No Family, No Future? Edited by Alan Booth, Ann C. Crouter, and Michael J. Shanahan. Westport, CT: Praeger.

Musick, Kelly, and Larry Bumpass. 1999. "How Do Prior Experiences in the Family Affect Transitions to Adulthood?" 69-102 in Transitions to Adulthood in a Changing Economy: No Work, No Family, No Future? edited by Alan Booth, Ann C. Crouter, and Michael J. Shanahan. Westport, CT: Praeger.

$\rightarrow$ Muthen, Bengt, and Linda K. Muthen. 2000. "Integrating Person-Centered and Variable- 
Centered Analyses: Growth Mixture Modeling with Latent Trajectory Classes." Alcoholism: Clinical and Experimental Research 24 (6): 882-91.

O’Connor, Thomas G., Joseph P. Allen, Kathy L. Bell, and Stuart T. Hauser. 1996. "Adolescent-Parent Relationships and Leaving Home in Young Adulthood." 39-52 in Leaving Home: Understanding the Transition to Adulthood, edited by Julia A. Graber and Judith Semon Dubas. San Francisco: Jossey-Bass.

Osgood, D. Wayne, Gretchen Ruth, Jacquelynne S. Eccles, Janis E. Jacobs, and Bonnie L. Barber. 2005. "Six Paths to Adulthood: Fast Starters, Parents without Careers, Educated Partners, Educated Singles, Working Singles, and Slow Starters." 320-55 in On the Frontier of Adulthood: Theory, Research, and Public Policy, edited by Richard A. Settersten Jr., Frank F. Furstenberg Jr., and Rubén G. Rumbaut. Chicago: University of Chicago Press.

Pecora, Peter J., James K. Whittaker, and Anthony N. Maluccio. 1992. The Child Welfare Challenge: Policy, Practice, and Research. New York: Aldine de Gruyter.

Propp, Jennifer, Debora M. Ortega, and Forest NewHeart. 2003. "Independence or Interdependence: Rethinking the Transition from "Ward of the Court' to Adulthood." Families in Society 84 (2): 259-66.

$\rightarrow$ Raftery, Adrian E. 1995. "Bayesian Model Selection in Social Research." Sociological Methodology 25:111-63.

Schoeni, Robert F., and Karen E. Ross. 2005. "Material Assistance from Families during the Transition to Adulthood." 396-416 in On the Frontier of Adulthood: Theory, Research, and Public Policy, edited by Richard A. Settersten Jr., Frank F. Furstenberg Jr., and Rubén G. Rumbaut. Chicago: University of Chicago Press.

Settersten, Richard A., Jr. 2005. "Social Policy and the Transition to Adulthood: Toward Stronger Institutions and Individual Capacities." 534-60 in On the Frontier of Adulthood: Theory, Research, and Public Policy, edited by Richard A. Settersten Jr., Frank F. Furstenberg Jr., and Rubén G. Rumbaut. Chicago: University of Chicago Press.

$\rightarrow$ Shanahan, Michael J. 2000. "Pathways to Adulthood in Changing Societies: Variability and Mechanisms in Life Course Perspective." Annual Review of Sociology 26:667-92.

$\rightarrow$ Sherbourne, Cathy D., and Anita L. Stewart. 1991. "The MOS Social Support Survey." Social Science and Medicine 32 (6): 705-14.

$\rightarrow$ Sroufe, L. Alan. 1997. "Psychopathology as an Outcome of Development." Development and Psychopathology 9 (2): 251-68.

Steinberg, Laurence. 1990. "Autonomy, Conflict, and Harmony in the Family Relationship." 255-76 in At the Threshold: The Developing Adolescent, edited by S. Shirley Feldman and Glen R. Elliott. Cambridge, MA: Harvard University Press.

$\rightarrow$ Surko, Michael, Ken Peake, Irwin Epstein, and Daniel Medeiros. 2005. "Multiple Risks, Multiple Worries, and Adolescent Coping: What Clinicians Need to Ask About." Social Work in Mental Health 3 (3): 261-85.

University of North Carolina, Carolina Population Center. n.d. "The National Longitudinal Study of Adolescent Health: Study Design.” http://www.cpc.unc.edu/ projects/addhealth/design (accessed February 11, 2007).

$\rightarrow$ Vander Stoep, Ann, Shirley A. Beresford, Noel S. Weiss, Barbara McKnight, Ana Mari Cauce, and Patricia Cohen. 2000. "Community-Based Study of the Transition to Adulthood for Adolescents with Psychiatric Disorder.” American Journal of Epidemiology 152 (4): 352-62.

Vermunt, Jeroen K., and Jay Magidson. 2005. Latent GOLD 4.0 User's Guide. Belmont, MA: Statistical Innovations.

$\rightarrow$ White, Lynn. 1994. "Coresidence and Leaving Home: Young Adults and Their Parents." Annual Review of Sociology 20:81-102.

WHO (World Health Organization). 1997. Composite International Diagnostic Interview (CIDI Core): Version 2.1. Geneva: WHO.

Wilkinson, Gary S. 1993. Wide Range Achievement Test-Revision 3. Wilmington, DE: Jastak.

$\rightarrow$ Wittenbrink, Bernd, James L. Hilton, and Pamela L. Gist. 1998. "In Search of Similarity: Stereotypes as Naive Theories in Social Categorization.” Social Cognition 16 (1): 31-55.

$\rightarrow$ Wulczyn, Fred, Joseph Kogan, and Brenda Jones Harden. 2003. "Placement Stability and Movement Trajectories." Social Service Review 77 (2): 212-36. 


\section{Social Service Review}

\section{Notes}

This study is based on the Midwest Evaluation of the Adult Functioning of Former Foster Youth, a collaborative research effort with cooperation and funding from the Illinois Department of Children and Family Services, the Wisconsin Department of Health and Family Services, and the Iowa Department of Human Services. Preparation of this article was supported by funding from the William T. Grant Foundation. Portions of the analysis were made possible in part by a grant (R03 MH070525) from the National Institute of Mental Health to the first author. The authors wish to acknowledge Lori Moreno and Andrea Ingram from the Illinois Department of Children and Family Services, Paula Brown and John Tuohy from the Wisconsin Department of Health and Family Services, and Holli Noble from the Iowa Department of Human Services. The authors also thank Amy Dworsky and the other members of the research team at Chapin Hall Center for Children, Kerryann DiLoreto and the interviewers at the University of Wisconsin Survey Center in Madison, and the individuals who participated in the study.

1. The fit statistics used to determine the number of latent classes are based on a sample that includes only cases with complete data $(n=720)$. After determining the number of classes in the model, available data were used to classify each case. Thus, all other reported results are based on all cases $(n=732)$.

2. For LCA with $n$ binary indicators, each additional class increases the number of parameters estimated and correspondingly reduces the degrees of freedom by an increment of $n+1$. In this analysis, there are six indicators for the dichotomous variables and two indicators for the ordinal variable. Consequently, the change in degrees of freedom for each additional class is $8+1=9$. Because calculation of BIC incorporates the number of parameters, the relatively large penalty for parsimony with addition of a single class is weighed against improvements in model fit with addition of that class. Class-by-class jumps in BIC (rather than single parameter increments) can highlight the choice between fit and parsimony. Such a choice is encountered in this analysis.

3. Modal assignment yielded the relative proportions of the sample for each class reported in table 2. Weighted assignment yielded the following proportions for classes 1-4, respectively: $0.416,0.385,0.145$, and 0.054 . 